\title{
Reductive dehalogenation of halogenated persistent organic pollutant by iron sulfides
}

\author{
YIN ZHONG ${ }^{1}$, DAN Li $^{1}$, XIFEN Zhu', WeILIN HUANG ${ }^{2}$
} AND PING'AN PENG ${ }^{1}$

${ }^{1}$ State Key Laboratory of Organic Geochemistry, Guangzhou Institute of Geochemistry, Chinese Academy of Sciences; zhongyin@gig.ac.cn; lidan20080831@126.com; zhuxf04@163.com; pinganp@gig.ac.cn;

${ }^{2}$ Department of Environmental Sciences, Rutgers, The State University of New Jersey, 14 College Farm Road, New Brunswick, NJ 08901 USA; whuang@envsci.rutgers.edu

Abstract: Halogenated persistent organic pollutant (POPs) are easily accumulated in soils and sediments, and can pose a serious health risk to human beings via food chain. Soils and sediments are generally rich in naturally occurring reactive minerals $\left(\mathrm{FeS}_{2}, \mathrm{Fe}_{3} \mathrm{~S}_{4}\right.$, amorphous $\left.\mathrm{FeS}\right)$, which may play an important role in the abiotic transformation of halogenated POPs. In this study, we investigated the reductive transformation kinetics, pathways and mechanism of brominated flame retardants (BFRs) and chlorinated organophosphate esters (Cl-OPEs) by amorphous FeS and FeS-doping nanoscale zero-valent iron (S-nZVI). It was found that only hexabromocyclododecane (HBCD) could be transformed by FeS, suggesting that FeS plays a key role in the fate of HBCD in anoxic environments. Although tetrabromobisphenol A (TBBPA), decabrominated diphenyl ether (BDE-209) and tri(2-chloroethyl) phosphate was not reactive with $\mathrm{FeS}$, they could be rapidly transformed by $\mathrm{S}$ nZVI, suggesting that S-nZVI has the great potential for the remediation of POPs-contaminated sites. The results obtained will be very helpful in improving our understanding of the abiotic transformation of POPs in soils and sediments and the major factors governing this process, thereby providing the scientific basis for risk assessment, control and remediation of POPs contamination in the environment. 